\title{
Convergence Theorem Based on a New Hybrid Projection Method for Finding a Common Solution of Generalized Equilibrium and Variational Inequality Problems in Banach Spaces
}

\author{
Siwaporn Saewan, Poom Kumam, and Kriengsak Wattanawitoon \\ Department of Mathematics, Faculty of Science, King Mongkut's University of \\ Technology Thonburi (KMUTT), Bangmod, Bangkok 10140, Thailand \\ Correspondence should be addressed to Poom Kumam, poom.kum@kmutt.ac.th \\ Received 26 October 2009; Accepted 3 January 2010 \\ Academic Editor: Simeon Reich \\ Copyright (C) 2010 Siwaporn Saewan et al. This is an open access article distributed under the \\ Creative Commons Attribution License, which permits unrestricted use, distribution, and \\ reproduction in any medium, provided the original work is properly cited. \\ The purpose of this paper is to introduce a new hybrid projection method for finding a common \\ element of the set of common fixed points of two relatively quasi-nonexpansive mappings, the \\ set of the variational inequality for an $\alpha$-inverse-strongly monotone, and the set of solutions of \\ the generalized equilibrium problem in the framework of a real Banach space. We obtain a strong \\ convergence theorem for the sequences generated by this process in a 2-uniformly convex and \\ uniformly smooth Banach space. Base on this result, we also get some new and interesting results. \\ The results in this paper generalize, extend, and unify some well-known strong convergence \\ results in the literature.
}

\section{Introduction}

Let $E$ be a real Banach space, $E^{*}$ the dual space of $E$. A Banach space $E$ is said to be strictly convex if $\|(x+y) / 2\|<1$ for all $x, y \in E$, with $\|x\|=\|y\|=1$ and $x \neq y$. Let $U=\{x \in E:\|x\|=1\}$ be the unit sphere of $E$. Then a Banach space $E$ is said to be smooth if the limit

$$
\lim _{t \rightarrow 0} \frac{\|x+t y\|-\|x\|}{t}
$$

exists for each $x, y \in U$. It is also said to be uniformly smooth if the limit is attained uniformly for $x, y \in U$. Let $E$ be a Banach space. The modulus of convexity of $E$ is the function 
$\delta:[0,2] \rightarrow[0,1]$ defined by

$$
\delta(\varepsilon)=\inf \left\{1-\left\|\frac{x+y}{2}\right\|: x, y \in E,\|x\|=\|y\|=1,\|x-y\| \geq \varepsilon\right\} .
$$

A Banach space $E$ is uniformly convex if and only if $\delta(\varepsilon)>0$ for all $\varepsilon \in(0,2]$. Let $p$ be a fixed real number with $p \geq 2$. A Banach space $E$ is said to be $p$-uniformly convex if there exists a constant $c>0$ such that $\delta(\varepsilon) \geq c \varepsilon^{p}$ for all $\varepsilon \in[0,2]$; see [1,2] for more details. Observe that every $p$-uniform convex is uniformly convex. One should note that no Banach space is $p$-uniform convex for $1<p<2$. It is well known that a Hilbert space is 2-uniformly convex, uniformly smooth. For each $p>1$, the generalized duality mapping $J_{p}: E \rightarrow 2^{E^{*}}$ is defined by

$$
J_{p}(x)=\left\{x^{*} \in E^{*}:\left\langle x, x^{*}\right\rangle=\|x\|^{p},\left\|x^{*}\right\|=\|x\|^{p-1}\right\}
$$

for all $x \in E$. In particular, $J=J_{2}$ is called the normalized duality mapping. If $E$ is a Hilbert space, then $J=I$, where $I$ is the identity mapping. It is also known that if $E$ is uniformly smooth, then $J$ is uniformly norm-to-norm continuous on each bounded subset of $E$.

Let $E$ be a real Banach space with norm $\|\cdot\|$ and $E^{*}$ denotes the dual space of $E$. Consider the functional defined by

$$
\phi(x, y)=\|x\|^{2}-2\langle x, J y\rangle+\|y\|^{2} \quad \forall x, y \in E .
$$

Observe that, in a Hilbert space $H,(1.4)$ reduces to $\phi(x, y)=\|x-y\|^{2}, x, y \in H$. The generalized projection $\Pi_{C}: E \rightarrow C$ is a map that assigns to an arbitrary point $x \in E$, the minimum point of the functional $\phi(x, y)$, that is, $\Pi_{C} x=\bar{x}$, where $\bar{x}$ is the solution to the minimization problem

$$
\phi(\bar{x}, x)=\inf _{y \in C} \phi(y, x)
$$

existence and uniqueness of the mapping $\Pi_{C}$ follow from the properties of the functional $\phi(x, y)$ and strict monotonicity of the mapping $J$ (see, e.g., [3-7]). In Hilbert spaces, $\Pi_{C}=P_{C}$. It is obvious from the definition of function $\phi$ that

$$
(\|y\|-\|x\|)^{2} \leq \phi(y, x) \leq(\|y\|+\|x\|)^{2}, \quad \forall x, y \in E .
$$

Remark 1.1. If $E$ is a reflexive, strictly convex, and smooth Banach space, then for $x, y \in E$, $\phi(x, y)=0$ if and only if $x=y$. It is sufficient to show that if $\phi(x, y)=0$, then $x=y$. From (2.13), we have $\|x\|=\|y\|$. This implies that $\langle x, J y\rangle=\|x\|^{2}=\|J y\|^{2}$. From the definition of $J$, one has $J x=J y$. Therefore, we have $x=y$; see $[5,7]$ for more details.

Next, we give some examples which are closed relatively quasi-nonexpansive (see

Example 1.2. Let $\Pi_{C}$ be the generalized projection from a smooth, strictly convex and reflexive Banach space $E$ onto a nonempty closed and convex subset $C$ of $E$. Then, $\Pi_{C}$ is a closed relatively quasi-nonexpansive mapping from $E$ onto $C$ with $F\left(\Pi_{C}\right)=C$. 
Let $E$ be a real Banach space and let $C$ be a nonempty closed and convex subset of $E$, and $A: C \rightarrow E^{*}$ be a mapping. The classical variational inequality problem for a mapping $\mathrm{A}$ is to find $x^{*} \in C$ such that

$$
\left\langle A x^{*}, y-x^{*}\right\rangle \geq 0, \quad \forall y \in C
$$

The set of solutions of (1.4) is denoted by $\operatorname{VI}(A, C)$. Recall that $\mathrm{A}$ is called

(i) monotone if

$$
\langle A x-A y, x-y\rangle \geq 0, \quad \forall x, y \in C
$$

(ii) an $\alpha$-inverse-strongly monotone if there exists a constant $\alpha>0$ such that

$$
\langle A x-A y, x-y\rangle \geq \alpha\|x-y\|^{2}, \quad \forall x, y \in C
$$

Such a problem is connected with the convex minimization problem, the complementary problem, and the problem of finding a point $x^{*} \in E$ satisfying $A x^{*}=0$.

Let $f$ be a bifunction from $C \times C$ to $\mathbb{R}$, where $\mathbb{R}$ denotes the set of real numbers. The equilibrium problem (for short, EP) is to find $x^{*} \in C$ such that

$$
f\left(x^{*}, y\right) \geq 0, \quad \forall y \in C
$$

The set of solutions of (1.10) is denoted by $\mathrm{EP}(f)$. Given a mapping $T: C \rightarrow E^{*}$, let $f(x, y)=\langle T x, y-x\rangle$ for all $x, y \in C$. Then $x^{*} \in \mathrm{EP}(f)$ if and only if $\left\langle T x^{*}, y-x^{*}\right\rangle \geq 0$ for all $y \in C$; that is, $x^{*}$ is a solution of the variational inequality. Numerous problems in physics, optimization, and economics reduce to find a solution of (1.10). Some methods have been proposed to solve the equilibrium problem; see, for instance, [9-11]. if

Let $C$ be a closed convex subset of $E$; a mapping $T: C \rightarrow C$ is said to be nonexpansive

$$
\|T x-T y\| \leq\|x-y\|, \quad \forall x, y \in C
$$

A point $x \in C$ is a fixed point of $T$ provided that $T x=x$. Denote by $F(T)$ the set of fixed points of $T$; that is, $F(T)=\{x \in C: T x=x\}$. Recall that a point $p$ in $C$ is said to be an asymptotic fixed point of $T$ [12] if $C$ contains a sequence $\left\{x_{n}\right\}$ which converges weakly to $p$ such that $\lim _{n \rightarrow \infty}\left\|x_{n}-T x_{n}\right\|=0$. The set of asymptotic fixed points of $T$ will be denoted by $\widehat{F(T)}$. A mapping $T$ from $C$ into itself is said to be relatively nonexpansive [13-15] if $\widehat{F(T)}=F(T)$ and $\phi(p, T x) \leq \phi(p, x)$ for all $x \in C$ and $p \in F(T)$. The asymptotic behavior of a relatively nonexpansive mapping was studied in [16-18]. $T$ is said to be $\phi$-nonexpansive, if $\phi(T x, T y) \leq$ $\phi(x, y)$ for $x, y \in C$. $T$ is said to be relatively quasi-nonexpansive if $F(T) \neq \emptyset$ and $\phi(p, T x) \leq$ $\phi(p, x)$ for $x \in C$ and $p \in F(T)$. A mapping $T$ in a Banach space $E$ is closed if $x_{n} \rightarrow x$ and $T x_{n} \rightarrow y$, then $T x=y$. 
Remark 1.3. The class of relatively quasi-nonexpansive mappings is more general than the class of relatively nonexpansive mappings [16-19] which requires the strong restriction $F(T)=\widehat{F(T)}$.

In Hilbert spaces $H$, Iiduka et al. [20] proved that the sequence $\left\{x_{n}\right\}$ defined by: $x_{1}=$ $x \in C$ and

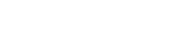

where $P_{C}$ is the metric projection of $H$ onto $C$, and $\left\{\lambda_{n}\right\}$ is a sequence of positive real numbers, and converges weakly to some element of $\operatorname{VI}(A, C)$.

It is well know that if $C$ is a nonempty closed and convex subset of a Hilbert space $H$ and $P_{C}: H \rightarrow C$ is the metric projection of $H$ onto $C$, then $P_{C}$ is nonexpansive. This fact actually characterizes Hilbert spaces and consequently, it is not available in more general Banach spaces. In this connection, Alber [4] recently introduced a generalized projection mapping $\Pi_{C}$ in a Banach space $E$ which is an analogue of the metric projection in Hilbert spaces.

In 2008, Iiduka and Takahashi [21] introduced the following iterative scheme for finding a solution of the variational inequality problem for inverse-strongly monotone $A$ in a 2-uniformly convex and uniformly smooth Banach space $E$ : $x_{1}=x \in C$ and

$$
x_{n+1}=\Pi_{C} J^{-1}\left(J x_{n}-\lambda_{n} A x_{n}\right)
$$

for every $n=1,2,3, \ldots$, where $\Pi_{C}$ is the generalized metric projection from $E$ onto $C, J$ is the duality mapping from $E$ into $E^{*}$, and $\left\{\lambda_{n}\right\}$ is a sequence of positive real numbers. They proved that the sequence $\left\{x_{n}\right\}$ generated by (1.13) converges weakly to some element of $\operatorname{VI}(A, C)$. defined by

Matsushita and Takahashi [22] introduced the following iteration: a sequence $\left\{x_{n}\right\}$

$$
x_{n+1}=\Pi_{C} J^{-1}\left(\alpha_{n} J x_{n}+\left(1-\alpha_{n}\right) J T x_{n}\right)
$$

where the initial guess element $x_{0} \in C$ is arbitrary, $\left\{\alpha_{n}\right\}$ is a real sequence in $[0,1], T$ is a relatively nonexpansive mapping, and $\Pi_{C}$ denotes the generalized projection from $E$ onto a closed convex subset $C$ of $E$. They proved that the sequence $\left\{x_{n}\right\}$ converges weakly to a fixed point of $T$. 
In 2005, Matsushita and Takahashi [19] proposed the following hybrid iteration method (it is also called the CQ method) with generalized projection for relatively nonexpansive mapping $T$ in a Banach space $E$ :

$$
\begin{gathered}
x_{0} \in C \text { chosen arbitrarily, } \\
y_{n}=J^{-1}\left(\alpha_{n} J x_{n}+\left(1-\alpha_{n}\right) J T x_{n}\right), \\
C_{n}=\left\{z \in C: \phi\left(z, y_{n}\right) \leq \phi\left(z, x_{n}\right)\right\}, \\
Q_{n}=\left\{z \in C:\left\langle x_{n}-z, J x_{0}-J x_{n}\right\rangle \geq 0\right\}, \\
x_{n+1}=\prod_{C_{n} \cap Q_{n}} x_{0} .
\end{gathered}
$$

They proved that $\left\{x_{n}\right\}$ converges strongly to $\Pi_{F(T)} x_{0}$, where $\Pi_{F(T)}$ is the generalized projection from $C$ onto $F(T)$.

Recently, Takahashi and Zembayashi [23] proposed the following modification of iteration (1.15) for a relatively nonexpansive mapping:

$$
\begin{gathered}
x_{0}=x \in C, \\
y_{n}=J^{-1}\left(\alpha_{n} J x_{n}+\left(1-\alpha_{n}\right) J S x_{n}\right), \\
u_{n} \in C \text { such that } f\left(u_{n}, y\right)+\frac{1}{r_{n}}\left\langle y-u_{n}, J u_{n}-J y_{n}\right\rangle \geq 0, \quad \forall y \in C, \\
H_{n}=\left\{z \in C: \phi\left(z, u_{n}\right) \leq \phi\left(z, x_{n}\right)\right\}, \\
W_{n}=\left\{z \in C:\left\langle x_{n}-z, J x-J x_{n}\right\rangle \geq 0\right\}, \\
x_{n+1}=\prod_{H_{n} \cap W_{n}} x,
\end{gathered}
$$

where $J$ is the duality mapping on $E$. Then, $\left\{x_{n}\right\}$ converges strongly to $\Pi_{F(S) \cap E P(f)} x$, where $\Pi_{F(S) \cap E P(f)}$ is the generalized projection of $E$ onto $F(S) \cap \operatorname{EP}(f)$. Also, Takahashi and Zembayashi [24] proved the following iteration for a relatively nonexpansive mapping:

$$
\begin{gathered}
y_{n}=J^{-1}\left(\alpha_{n} J x_{n}+\left(1-\alpha_{n}\right) J S x_{n}\right), \\
u_{n} \in C \text { such that } f\left(u_{n}, y\right)+\frac{1}{r_{n}}\left\langle y-u_{n}, J u_{n}-J y_{n}\right\rangle \geq 0, \quad \forall y \in C, \\
C_{n+1}=\left\{z \in C_{n}: \phi\left(z, u_{n}\right) \leq \phi\left(z, x_{n}\right)\right\}, \\
x_{n+1}=\prod_{C_{n+1}} x,
\end{gathered}
$$


where $J$ is the duality mapping on $E$. Then, $\left\{x_{n}\right\}$ converges strongly to $\Pi_{F(S) \cap E P(f)} x$, where $\Pi_{F(S) \cap E P(f)}$ is the generalized projection of $E$ onto $F(S) \cap \mathrm{EP}(f)$. Qin and Su [25] proved the following iteration for relatively nonexpansive mappings $T$ in a Banach space $E$ :

$$
\begin{gathered}
x_{0} \in C, \quad \text { chosen arbitrarily, } \\
y_{n}=J^{-1}\left(\alpha_{n} J x_{n}+\left(1-\alpha_{n}\right) J T z_{n}\right), \\
z_{n}=J^{-1}\left(\beta_{n} J x_{n}+\left(1-\beta_{n}\right) J T x_{n}\right), \\
C_{n}=\left\{v \in C: \phi\left(v, y_{n}\right) \leq \alpha_{n} \phi\left(v, x_{n}\right)+\left(1-\alpha_{n}\right) \phi\left(v, z_{n}\right)\right\}, \\
Q_{n}=\left\{v \in C:\left\langle J x_{0}-J x_{n}, x_{n}-v\right\rangle \geq 0\right\}, \\
x_{n+1}=\prod_{C_{n} \cap Q_{n}} x_{0},
\end{gathered}
$$

the sequence $\left\{x_{n}\right\}$ generated by (1.18) converges strongly to $\Pi_{F(T)} x_{0}$.

In 2009, Wei et al. [26] proved the following iteration for two relatively nonexpansive mappings in a Banach space $E$ :

$$
\begin{gathered}
x_{0} \in C, \\
J z_{n}=\alpha_{n} J x_{n}+\left(1-\alpha_{n}\right) J T x_{n}, \\
J u_{n}=\left(\beta_{n} J x_{n}+\left(1-\beta_{n}\right) J S z_{n}\right), \\
H_{n}=\left\{v \in C: \phi\left(v, u_{n}\right) \leq \beta_{n} \phi\left(v, x_{n}\right)+\left(1-\beta_{n}\right) \phi\left(v, z_{n}\right) \leq \phi\left(v, x_{n}\right)\right\}, \\
W_{n}=\left\{z \in C:\left\langle z-x_{n}, J x_{0}-J x_{n}\right\rangle \leq 0\right\}, \\
x_{n+1}=Q_{H_{n} \cap W_{n}} x_{0} ;
\end{gathered}
$$

if $\left\{\alpha_{n}\right\}$ and $\left\{\beta_{n}\right\}$ are sequences in $[0,1)$ such that $\alpha_{n} \leq 1-\delta_{1}$ and $\beta_{n} \leq 1-\delta_{2}$ for some $\delta_{1}, \delta_{2} \in(0,1)$, then $\left\{x_{n}\right\}$ generated by (1.19) converges strongly to a point $Q_{F(T) \cap F(S)} x_{0}$, where the mapping $Q_{C}$ of $E$ onto $C$ is the generalized projection. Very recently, Cholamjiak [27] proved the following iteration:

$$
\begin{gathered}
z_{n}=\prod_{C} J^{-1}\left(J x_{n}-\lambda_{n} A x_{n}\right), \\
y_{n}=J^{-1}\left(\alpha_{n} J x_{n}+\beta_{n} J T x_{n}+\gamma_{n} J S z_{n}\right), \\
u_{n} \in C \text { such that } f\left(u_{n}, y\right)+\frac{1}{r_{n}}\left\langle y-u_{n}, J u_{n}-J y_{n}\right\rangle \geq 0, \quad \forall y \in C, \\
C_{n+1}=\left\{z \in C_{n}: \phi\left(z, u_{n}\right) \leq \phi\left(z, x_{n}\right)\right\}, \\
x_{n+1}=\prod_{C_{n+1}} x_{0},
\end{gathered}
$$

where $J$ is the duality mapping on $E$. Assume that $\alpha_{n}, \beta_{n}$, and $\gamma_{n}$ are sequences in $[0,1]$. Then $\left\{x_{n}\right\}$ converges strongly to $q=\Pi_{F} x_{0}$, where $F:=F(T) \cap F(S) \cap \operatorname{EP}(f) \cap \operatorname{VI}(A, C)$. 
Motivated and inspired by Iiduka and Takahashi [21], Takahashi and Zembayashi [23, 24], Wei et al. [26], Cholamjiak [27], and Kumam and Wattanawitoon [28], we introduce a new hybrid projection iterative scheme which is difference from the algorithm (1.20) of Cholamjiak in [27, Theorem 3.1] for two relatively quasi-nonexpansive mappings in a Banach space. For an initial point $x_{0} \in E$ with $x_{1}=\Pi_{C_{1}} x_{0}$ and $C_{1}=C$, define a sequence $\left\{x_{n}\right\}$ as follows:

$$
\begin{gathered}
w_{n}=\prod_{C} J^{-1}\left(J x_{n}-\lambda_{n} A x_{n}\right), \\
z_{n}=J^{-1}\left(\beta_{n} J x_{n}+\left(1-\beta_{n}\right) J T w_{n}\right), \\
y_{n}=J^{-1}\left(\alpha_{n} J x_{n}+\left(1-\alpha_{n}\right) J S z_{n}\right), \\
u_{n} \in C \quad \text { such that } f\left(u_{n}, y\right)+\frac{1}{r_{n}}\left\langle y-u_{n}, J u_{n}-J y_{n}\right\rangle \geq 0, \quad \forall y \in C, \\
C_{n+1}=\left\{z \in C_{n}: \phi\left(z, u_{n}\right) \leq \alpha_{n} \phi\left(z, x_{n}\right)+\left(1-\alpha_{n}\right) \phi\left(z, z_{n}\right) \leq \phi\left(z, x_{n}\right)\right\}, \\
x_{n+1}=\prod_{C_{n+1}} x_{0}, \quad \forall n \geq 1,
\end{gathered}
$$

where $J$ is the duality mapping on $E$. Then, we prove that under certain appropriate conditions on the parameters, the sequences $\left\{x_{n}\right\}$ and $\left\{u_{n}\right\}$ generated by (1.21) converge

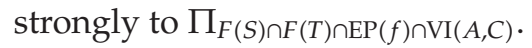

The results presented in this paper improve and extend the corresponding results announced by Iiduka and Takahashi [21], Wei et al. [26], Kumam and Wattanawitoon [28], and many other authors in the literature.

\section{Preliminaries}

We also need the following lemmas for the proof of our main results.

Lemma 2.1 (Beauzamy [29] and $\mathrm{Xu}$ [30]). If $E$ is a 2-uniformly convex Banach space, then, for all $x, y \in E$ we have

$$
\|x-y\| \leq \frac{2}{c^{2}}\|J x-J y\|
$$

where $J$ is the normalized duality mapping of $E$ and $0<c \leq 1$.

The best constant $1 / c$ in the Lemma is called the $p$-uniformly convex constant of $E$.

Lemma 2.2 (Beauzamy [29] and Zălinescu [31]). If E is a p-uniformly convex Banach space and $p$ is a given real number with $p \geq 2$, then for all $x, y \in E, J_{x} \in J_{p}(x)$, and $J_{y} \in J_{p}(y)$,

$$
\langle x-y, J x-J y\rangle \geq \frac{c^{p}}{2^{p-2} p}\|x-y\|^{p}
$$

where $J_{p}$ is the generalized duality mapping of $E$ and $1 / c$ is the $p$-uniformly convexity constant of $E$. 
Lemma 2.3 (Kamimura and Takahashi [6]). Let E be a uniformly convex and smooth Banach space and let $\left\{x_{n}\right\}$ and $\left\{y_{n}\right\}$ be two sequences of $E$. If $\phi\left(x_{n}, y_{n}\right) \rightarrow 0$ and either $\left\{x_{n}\right\}$ or $\left\{y_{n}\right\}$ is bounded, then $\left\|x_{n}-y_{n}\right\| \rightarrow 0$.

Lemma 2.4 (Alber [4]). Let $C$ be a nonempty closed and convex subset of a smooth Banach space $E$ and $x \in E$. Then, $x_{0}=\Pi_{C} x$ if and only if

$$
\left\langle x_{0}-y, J x-J x_{0}\right\rangle \geq 0, \quad \forall y \in C
$$

Lemma 2.5 (Alber [4]). Let $E$ be a reflexive, strictly convex, and smooth Banach space, let $C$ be a nonempty closed and convex subset of $E$, and let $x \in E$. Then

$$
\phi\left(y, \Pi_{C} x\right)+\phi\left(\Pi_{C} x, x\right) \leq \phi(y, x), \quad \forall y \in C .
$$

Lemma 2.6 (Qin et al. [8]). Let E be a uniformly convex and smooth Banach space, let $C$ be a closed and convex subset of $E$, and let $T$ be a closed relatively quasi-nonexpansive mapping from $C$ into itself. Then $F(T)$ is a closed and convex subset of $C$.

For solving the equilibrium problem for a bifunction $f: C \times C \rightarrow \mathbb{R}$, let us assume that $f$ satisfies the following conditions:

(A1) $f(x, x)=0$ for all $x \in C$;

(A2) $f$ is monotone, that is, $f(x, y)+f(y, x) \leq 0$ for all $x, y \in C$;

(A3) for each $x, y, z \in C$,

$$
\lim _{t \downarrow 0} f(t z+(1-t) x, y) \leq f(x, y)
$$

(A4) for each $x \in C, y \mapsto f(x, y)$ is convex and lower semi-continuous.

Lemma 2.7 (Blum and Oettli [9]). Let $C$ be a closed and convex subset of a smooth, strictly convex and reflexive Banach space $E$, let $f$ be a bifunction from $C \times C$ to $\mathbb{R}$ satisfying (A1)-(A4), and let $r>0$ and $x \in E$. Then, there exists $z \in C$ such that

$$
f(z, y)+\frac{1}{r}\langle y-z, J z-J x\rangle \geq 0, \quad \forall y \in C
$$

Lemma 2.8 (Combettes and Hirstoaga [10]). Let $C$ be a closed and convex subset of a uniformly smooth, strictly convex and reflexive Banach space $E$ and let $f$ be a bifunction from $C \times C$ to $\mathbb{R}$ satisfying (A1)-(A4). For $r>0$ and $x \in E$, define a mapping $T_{r}: E \rightarrow C$ as follows:

$$
T_{r} x=\left\{z \in C: f(z, y)+\frac{1}{r}\langle y-z, J z-J x\rangle \geq 0, \forall y \in C\right\}
$$


for all $x \in C$. Then the following holds:

(1) $T_{r}$ is single-valued;

(2) $T_{r}$ is a firmly nonexpansive-type mapping, for all $x, y \in E$,

$$
\left\langle T_{r} x-T_{r} y, J T_{r} x-J T_{r} y\right\rangle \leq\left\langle T_{r} x-T_{r} y, J x-J y\right\rangle
$$

(3) $F\left(T_{r}\right)=\mathrm{EP}(f)$;

(4) $\mathrm{EP}(f)$ is closed and convex.

Lemma 2.9 (Takahashi and Zembayashi [24]). Let $C$ be a closed and convex subset of a smooth, strictly convex, and reflexive Banach space $E$, let $f$ be a bifunction from $C \times C$ to $\mathbb{R}$ satisfying (A1)(A4), and let $r>0$. Then, for $x \in E$ and $q \in F\left(T_{r}\right)$,

$$
\phi\left(q, T_{r} x\right)+\phi\left(T_{r} x, x\right) \leq \phi(q, x) .
$$

Let $E$ be a reflexive, strictly convex, and smooth Banach space and $J$ the duality mapping from $E$ into $E^{*}$. Then $J^{-1}$ is also single value, one-to-one, surjective, and it is the duality mapping from $E^{*}$ into $E$. We make use of the following mapping $V$ studied in Alber [4]:

$$
V\left(x, x^{*}\right)=\|x\|^{2}-2\left\langle x, x^{*}\right\rangle+\left\|x^{*}\right\|^{2}
$$

for all $x \in E$ and $x^{*} \in E^{*}$, that is, $V\left(x, x^{*}\right)=\phi\left(x, J^{-1}\left(x^{*}\right)\right)$.

Lemma 2.10 (Alber [4]). Let E be a reflexive, strictly convex, and smooth Banach space and let $V$ be as in (2.10). Then

$$
V\left(x, x^{*}\right)+2\left\langle J^{-1}\left(x^{*}\right)-x, y^{*}\right\rangle \leq V\left(x, x^{*}+y^{*}\right)
$$

for all $x \in E$ and $x^{*}, y^{*} \in E^{*}$.

Let $A$ be an inverse-strongly monotone of $C$ into $E^{*}$ which is said to be hemicontinuous if for all $x, y \in C$, the mapping $F$ of $[0,1]$ into $E^{*}$, defined by $F(t)=A(t x+(1-t) y)$, is continuous with respect to the weak* topology of $E^{*}$. We define by $N_{C}(v)$ the normal cone for $C$ at a point $v \in C$; that is,

$$
N_{C}(v)=\left\{x^{*} \in E^{*}:\left\langle v-y, x^{*}\right\rangle \geq 0, \forall y \in C\right\} .
$$

Theorem 2.11 (Rockafellar [32]). Let $C$ be a nonempty, closed and convex subset of a Banach space $E$, and $A$ a monotone, hemicontinuous mapping of $C$ into $E^{*}$. Let $T \subset E \times E^{*}$ be a mapping defined as follows:

$$
T v= \begin{cases}A v+N_{C}(v), & v \in C \\ \emptyset, & \text { otherwise }\end{cases}
$$

Then $T$ is maximal monotone and $T^{-1} 0=\operatorname{VI}(A, C)$. 


\section{Main Results}

In this section, we establish a new hybrid iterative scheme for finding a common element of the set of solutions of an equilibrium problems, the common fixed point set of two relatively quasi-nonexpansive mappings, and the solution set of variational inequalities for $\alpha$-inverse strongly monotone in a 2-uniformly convex and uniformly smooth Banach space.

Theorem 3.1. Let $C$ be a nonempty closed and convex subset of a 2-uniformly convex and uniformly smooth Banach space $E$. Let $f$ be a bifunction from $C \times C$ to $\mathbb{R}$ satisfying (A1)-(A4) and let $A$ be an $\alpha$-inverse-strongly monotone mapping of $C$ into $E^{*}$ satisfying $\|A y\| \leq\|A y-A u\|$, for all $y \in C$ and $u \in \operatorname{VI}(A, C) \neq \emptyset$. Let $T, S: C \rightarrow C$ be closed relatively quasi-nonexpansive mappings such that $\Omega:=F(T) \cap F(S) \cap \mathrm{EP}(f) \cap \operatorname{VI}(A, C) \neq \emptyset$. For an initial point $x_{0} \in E$ with $x_{1}=\Pi_{C_{1}} x_{0}$ and $C_{1}=C$, we define the sequence $\left\{x_{n}\right\}$ as follows:

$$
\begin{gathered}
w_{n}=\prod_{C} J^{-1}\left(J x_{n}-\lambda_{n} A x_{n}\right), \\
z_{n}=J^{-1}\left(\beta_{n} J x_{n}+\left(1-\beta_{n}\right) J T w_{n}\right), \\
y_{n}=J^{-1}\left(\alpha_{n} J x_{n}+\left(1-\alpha_{n}\right) J S z_{n}\right), \\
u_{n} \in C \text { such that } f\left(u_{n}, y\right)+\frac{1}{r_{n}}\left\langle y-u_{n}, J u_{n}-J y_{n}\right\rangle \geq 0, \quad \forall y \in C, \\
C_{n+1}=\left\{z \in C_{n}: \phi\left(z, u_{n}\right) \leq \alpha_{n} \phi\left(z, x_{n}\right)+\left(1-\alpha_{n}\right) \phi\left(z, z_{n}\right) \leq \phi\left(z, x_{n}\right)\right\}, \\
x_{n+1}=\prod_{C_{n+1}} x_{0}, \quad \forall n \geq 1,
\end{gathered}
$$

where $J$ is the duality mapping on $E,\left\{\alpha_{n}\right\}$ and $\left\{\beta_{n}\right\}$ are sequences in $[0,1]$ such that $\alpha_{n} \leq 1-\delta_{1}$ and $\beta_{n} \leq 1-\delta_{2}$, for some $\delta_{1}, \delta_{2} \in(0,1),\left\{r_{n}\right\} \subseteq(0,2 \alpha)$ and $\left\{\lambda_{n}\right\} \subset[a, b]$ for some $a, b$ with $0<a<b<c^{2} \alpha / 2$, where $1 / c$ is the 2-uniformly convexity constant of $E$. Then $\left\{x_{n}\right\}$ converges strongly to $p \in \Omega$, where $p=\Pi_{\Omega} x_{0}$.

Proof. We have several steps to prove this theorem as follows:

Step 1. We show that $C_{n+1}$ is closed and convex.

Clearly $C_{1}=C$ is closed and convex. Suppose that $C_{n}$ is closed and convex for each $n \in \mathbb{N}$. Since for any $z \in C_{n}$, we know that

$$
\phi\left(z, u_{n}\right) \leq \phi\left(z, x_{n}\right)
$$

is equivalent to

$$
2\left\langle z, J x_{n}-J u_{n}\right\rangle \leq\left\|x_{n}\right\|^{2}-\left\|u_{n}\right\|^{2} .
$$

So, $C_{n+1}$ is closed and convex. Then, by induction, $C_{n}$ is closed and convex for all $n \geq 1$. 
Step 2. We show that $\left\{x_{n}\right\}$ is well defined.

Put $u_{n}=T_{r_{n}} y_{n}$ for all $n \geq 0$. On the other hand, from Lemma 2.8 one has $T_{r_{n}}$ is relatively quasi-nonexpansive mappings and $\Omega \subset C_{1}=C$. Supposing $\Omega \subset C_{k}$ for $k \in \mathbb{N}$, by the convexity of $\|\cdot\|^{2}$, for each $q \in \Omega \subset C_{k}$, we have

$$
\begin{aligned}
\phi\left(q, u_{k}\right) & =\phi\left(q, T_{r_{k}} y_{k}\right) \\
& \leq \phi\left(q, y_{k}\right) \\
& =\phi\left(q, J^{-1}\left(\alpha_{k} J x_{k}+\left(1-\alpha_{k}\right) J S z_{k}\right)\right) \\
& =\|q\|^{2}-2\left\langle q, \alpha_{k} J x_{k}+\left(1-\alpha_{k}\right) J S z_{k}\right\rangle+\left\|\alpha_{k} J x_{k}+\left(1-\alpha_{k}\right) J S z_{k}\right\|^{2} \\
& \leq\|q\|^{2}-2 \alpha_{k}\left\langle q, J x_{k}\right\rangle-2\left(1-\alpha_{k}\right)\left\langle q, J S z_{k}\right\rangle+\alpha_{k}\left\|x_{k}\right\|^{2}+\left(1-\alpha_{k}\right)\left\|S z_{k}\right\|^{2} \\
& =\alpha_{k} \phi\left(q, x_{k}\right)+\left(1-\alpha_{k}\right) \phi\left(q, S z_{k}\right) \\
& \leq \alpha_{k} \phi\left(q, x_{k}\right)+\left(1-\alpha_{k}\right) \phi\left(q, z_{k}\right),
\end{aligned}
$$

and so

$$
\begin{aligned}
\phi\left(q, z_{k}\right) & =\phi\left(q, J^{-1}\left(\beta_{k} J x_{k}+\left(1-\beta_{k}\right) J T w_{k}\right)\right) \\
& =\|q\|^{2}-2\left\langle q, \beta_{k} J x_{k}+\left(1-\beta_{k}\right) J T w_{k}\right\rangle+\left\|\beta_{k} J x_{k}+\left(1-\beta_{k}\right) J T w_{k}\right\|^{2} \\
& \leq\|q\|^{2}-2 \beta_{k}\left\langle q, J x_{k}\right\rangle-2\left(1-\beta_{k}\right)\left\langle q, J T w_{k}\right\rangle+\beta_{k}\left\|J x_{k}\right\|^{2}+\left(1-\beta_{k}\right)\left\|J T w_{k}\right\|^{2} \\
& =\beta_{k} \phi\left(q, x_{k}\right)+\left(1-\beta_{k}\right) \phi\left(q, T w_{k}\right) \\
& \leq \beta_{k} \phi\left(q, x_{k}\right)+\left(1-\beta_{k}\right) \phi\left(q, w_{k}\right) .
\end{aligned}
$$

For all $q \in \Omega$, we know from Lemma 2.10, that

$$
\begin{aligned}
\phi\left(q, w_{k}\right) & =\phi\left(q, \Pi_{C} J^{-1}\left(J x_{k}-\lambda_{k} A x_{k}\right)\right) \\
& \leq \phi\left(q, J^{-1}\left(J x_{k}-\lambda_{k} A x_{k}\right)\right) \\
& =V\left(q, J x_{k}-\lambda_{k} A x_{k}\right) \\
& \leq V\left(q,\left(J x_{k}-\lambda_{k} A x_{k}\right)+\lambda_{k} A x_{k}\right)-2\left\langle J^{-1}\left(J x_{k}-\lambda_{k} A x_{k}\right)-q, \lambda_{k} A x_{k}\right\rangle \\
& =V\left(q, J x_{k}\right)-2 \lambda_{k}\left\langle J^{-1}\left(J x_{k}-\lambda_{k} A x_{k}\right)-q, A x_{k}\right\rangle \\
& =\phi\left(q, x_{k}\right)-2 \lambda_{k}\left\langle x_{k}-q, A x_{k}\right\rangle+2\left\langle J^{-1}\left(J x_{k}-\lambda_{k} A x_{k}\right)-x_{k},-\lambda_{k} A x_{k}\right\rangle .
\end{aligned}
$$


Since $q \in \operatorname{VI}(A, C)$ and from $A$ being an $\alpha$-inverse-strongly monotone, we get

$$
\begin{aligned}
-2 \lambda_{k}\left\langle x_{k}-q, A x_{k}\right\rangle & =-2 \lambda_{k}\left\langle x_{k}-q, A x_{k}-A q\right\rangle-2 \lambda_{k}\left\langle x_{k}-q, A q\right\rangle \\
& \leq-2 \lambda_{k}\left\langle x_{k}-q, A x_{k}-A q\right\rangle \\
& =-2 \alpha \lambda_{k}\left\|A x_{k}-A q\right\|^{2} .
\end{aligned}
$$

From Lemma 2.1 and $A$ being an $\alpha$-inverse-strongly monotone, we obtain

$$
\begin{aligned}
2\left\langle J^{-1}\left(J x_{k}-\lambda_{k} A x_{k}\right)-x_{k},-\lambda_{k} A x_{k}\right\rangle & =2\left\langle J^{-1}\left(J x_{k}-\lambda_{k} A x_{k}\right)-J^{-1}\left(J x_{k}\right),-\lambda_{k} A x_{k}\right\rangle \\
& \leq 2\left\|J^{-1}\left(J x_{k}-\lambda_{k} A x_{k}\right)-J^{-1}\left(J x_{k}\right)\right\|\left\|\lambda_{k} A x_{k}\right\| \\
& \leq \frac{4}{c^{2}}\left\|J J^{-1}\left(J x_{k}-\lambda_{k} A x_{k}\right)-J J^{-1}\left(J x_{k}\right)\right\|\left\|\lambda_{k} A x_{k}\right\| \\
& =\frac{4}{c^{2}}\left\|J x_{k}-\lambda_{k} A x_{k}-J x_{k}\right\|\left\|\lambda_{k} A x_{k}\right\| \\
& =\frac{4}{c^{2}}\left\|\lambda_{k} A x_{k}\right\|^{2} \\
& =\frac{4}{c^{2}} \lambda_{k}^{2}\left\|A x_{k}\right\|^{2} \\
& \leq \frac{4}{c^{2}} \lambda_{k}^{2}\left\|A x_{k}-A q\right\|^{2} .
\end{aligned}
$$

Substituting (3.7) and (3.8) into (3.6), we have

$$
\begin{aligned}
\phi\left(q, w_{k}\right) & \leq \phi\left(q, x_{k}\right)-2 \alpha \lambda_{k}\left\|A x_{k}-A q\right\|^{2}+\frac{4}{c^{2}} \lambda_{k}^{2}\left\|A x_{k}-A q\right\|^{2} \\
& =\phi\left(q, x_{k}\right)+2 \lambda_{k}\left(\frac{2}{c^{2}} \lambda_{k}-\alpha\right)\left\|A x_{k}-A q\right\|^{2} \\
& \leq \phi\left(q, x_{k}\right) .
\end{aligned}
$$

Replacing (3.9) into (3.5), we get

$$
\phi\left(q, z_{k}\right) \leq \phi\left(q, x_{k}\right)
$$

Substituting (3.10) into (3.4), we also have

$$
\begin{aligned}
\phi\left(q, u_{k}\right) & \leq \alpha_{k} \phi\left(q, x_{k}\right)+\left(1-\alpha_{k}\right) \phi\left(q, x_{k}\right), \\
& =\phi\left(q, x_{k}\right) .
\end{aligned}
$$

This shows that $q \in C_{k+1}$ and hence, $\Omega \subset C_{k+1}$. Hence, $\Omega \subset C_{n}$ for all $n \geq 1$. This implies that the sequence $\left\{x_{n}\right\}$ is well defined. 
Step 3. We show that $\lim _{n \rightarrow \infty} \phi\left(x_{n}, x_{0}\right)$ exists and $\left\{x_{n}\right\}$ is bounded.

From $x_{n}=\Pi_{C_{n}} x_{0}$ and $x_{n+1}=\Pi_{C_{n+1}} x_{0}$, we have

$$
\phi\left(x_{n}, x_{0}\right) \leq \phi\left(x_{n+1}, x_{0}\right), \quad \forall n \geq 1
$$

and from Lemma 2.5 , we have

$$
\begin{aligned}
\phi\left(x_{n}, x_{0}\right) & =\phi\left(\Pi_{C_{n}}\left(x_{0}\right), x_{0}\right) \\
& \leq \phi\left(p, x_{0}\right)-\phi\left(p, x_{n}\right) \\
& \leq \phi\left(p, x_{0}\right), \quad \forall p \in \Omega .
\end{aligned}
$$

From (3.12) and (3.13), then $\left\{\phi\left(x_{n}, x_{0}\right)\right\}$ are nondecreasing and bounded. So, we obtain that $\lim _{n \rightarrow \infty} \phi\left(x_{n}, x_{0}\right)$ exists. In particular, by (1.6), the sequence $\left\{\left(\left\|x_{n}\right\|-\left\|x_{0}\right\|\right)^{2}\right\}$ is bounded. This implies that $\left\{x_{n}\right\}$ is also bounded.

Step 4. We show that $\left\{x_{n}\right\}$ is a Cauchy sequence in $C$.

Since $x_{m}=\Pi_{C_{m}} x_{0} \in C_{m} \subset C_{n}$, for $m>n$, by Lemma 2.5, we have

$$
\begin{aligned}
\phi\left(x_{m}, x_{n}\right) & =\phi\left(x_{m}, \Pi_{C_{n}} x_{0}\right) \\
& \leq \phi\left(x_{m}, x_{0}\right)-\phi\left(\Pi_{C_{n}} x_{0}, x_{0}\right) \\
& =\phi\left(x_{m}, x_{0}\right)-\phi\left(x_{n}, x_{0}\right) .
\end{aligned}
$$

Taking $m, n \rightarrow \infty$, we have $\phi\left(x_{m}, x_{n}\right) \rightarrow 0$. We have $\lim _{n \rightarrow \infty} \phi\left(x_{n+1}, x_{0}\right)=0$. From Lemma 2.3, we get $\lim _{n \rightarrow \infty}\left\|x_{n+1}-x_{0}\right\|=0$. Thus $\left\{x_{n}\right\}$ is a Cauchy sequence.

Step 5. We cliam that $\left\|J u_{n}-J x_{n}\right\| \rightarrow 0$, as $n \rightarrow \infty$.

By the completeness of $E$, the closedness of $C$ and $\left\{x_{n}\right\}$ is a Cauchy sequence (from Step 4); we can assume that there exists $p \in C$ such that $\left\{x_{n}\right\} \rightarrow p$ as $n \rightarrow \infty$.

By definition of $\Pi_{C_{n}} x_{0}$, we have

$$
\begin{aligned}
\phi\left(x_{n+1}, x_{n}\right) & =\phi\left(x_{n+1}, \Pi_{C_{n}} x_{0}\right) \\
& \leq \phi\left(x_{n+1}, x_{0}\right)-\phi\left(\Pi_{C_{n}} x_{0}, x_{0}\right) \\
& =\phi\left(x_{n+1}, x_{0}\right)-\phi\left(x_{n}, x_{0}\right) .
\end{aligned}
$$

Since $\lim _{n \rightarrow \infty} \phi\left(x_{n}, x_{0}\right)$ exists, we get

$$
\lim _{n \rightarrow \infty} \phi\left(x_{n+1}, x_{n}\right)=0
$$

It follow form Lemma 2.3, that

$$
\lim _{n \rightarrow \infty}\left\|x_{n+1}-x_{n}\right\|=0
$$


Since $x_{n+1}=\prod_{C_{n+1}} x_{0} \in C_{n+1} \subset C_{n}$ and from the definition of $C_{n+1}$, we have

$$
\phi\left(x_{n+1}, u_{n}\right) \leq \phi\left(x_{n+1}, x_{n}\right), \quad \forall n \geq 1
$$

and so

$$
\lim _{n \rightarrow \infty} \phi\left(x_{n+1}, u_{n}\right)=0
$$

Hence

$$
\lim _{n \rightarrow \infty}\left\|x_{n+1}-u_{n}\right\|=0
$$

By using the triangle inequality, we obtain

$$
\begin{aligned}
\left\|u_{n}-x_{n}\right\| & =\left\|u_{n}-x_{n+1}+x_{n+1}-x_{n}\right\| \\
& \leq\left\|u_{n}-x_{n+1}\right\|+\left\|x_{n+1}-x_{n}\right\| .
\end{aligned}
$$

By (3.17), (3.20), we get

$$
\lim _{n \rightarrow \infty}\left\|u_{n}-x_{n}\right\|=0
$$

Since $J$ is uniformly norm-to-norm continuous on bounded subsets of $E$, we have

$$
\lim _{n \rightarrow \infty}\left\|J u_{n}-J x_{n}\right\|=0 .
$$

Step 6. Show that $x_{n} \rightarrow p \in \mathrm{EP}(f)$.

Applying (3.4) and (3.11), we get $\phi\left(p, y_{n}\right) \leq \phi\left(p, x_{n}\right)$. From Lemma 2.9 and $u_{n}=T_{r_{n}} y_{n}$, we observe that

$$
\begin{aligned}
\phi\left(u_{n}, y_{n}\right) & =\phi\left(T_{r_{n}} y_{n}, y_{n}\right) \\
& \leq \phi\left(p, y_{n}\right)-\phi\left(p, T_{r_{n}} y_{n}\right) \\
& \leq \phi\left(p, x_{n}\right)-\phi\left(p, T_{r_{n}} y_{n}\right) \\
& =\phi\left(p, x_{n}\right)-\phi\left(p, u_{n}\right) \\
& =\|p\|^{2}-2\left\langle p, J x_{n}\right\rangle+\left\|x_{n}\right\|^{2}-\left(\|p\|^{2}-2\left\langle p, J u_{n}\right\rangle+\left\|u_{n}\right\|^{2}\right) \\
& =\left\|x_{n}\right\|^{2}-\left\|u_{n}\right\|^{2}-2\left\langle p, J x_{n}-J u_{n}\right\rangle \\
& \leq\left\|x_{n}-u_{n}\right\|\left(\left\|x_{n}+u_{n}\right\|\right)+2\|p\|\left\|J x_{n}-J u_{n}\right\| .
\end{aligned}
$$


From (3.22), (3.23) and Lemma 2.3, we get

$$
\lim _{n \rightarrow \infty}\left\|u_{n}-y_{n}\right\|=0
$$

Since $J$ is uniformly norm-to-norm continuous, we obtain

$$
\lim _{n \rightarrow \infty}\left\|J u_{n}-J y_{n}\right\|=0
$$

From $r_{n}>0$, we have $\left\|J u_{n}-J y_{n}\right\| / r_{n} \rightarrow 0$ as $n \rightarrow \infty$ and

$$
f\left(u_{n}, y\right)+\frac{1}{r_{n}}\left\langle y-u_{n}, J u_{n}-J y_{n}\right\rangle \geq 0, \quad \forall y \in C .
$$

By (A2), that

$$
\begin{aligned}
\left\|y-u_{n}\right\| \frac{\left\|J u_{n}-J y_{n}\right\|}{r_{n}} & \geq \frac{1}{r_{n}}\left\langle y-u_{n}, J u_{n}-J y_{n}\right\rangle \\
& \geq-f\left(u_{n}, y\right) \\
& \geq f\left(y, u_{n}\right), \quad \forall y \in C
\end{aligned}
$$

and $u_{n} \rightarrow p$, we get $f(y, p) \leq 0$ for all $y \in C$. For $0<t<1$, define $y_{t}=t y+(1-t) p$. Then $y_{t} \in C$ which implies that $f\left(y_{t}, p\right) \leq 0$. From (A1), we obtain that

$$
0=f\left(y_{t}, y_{t}\right) \leq t f\left(y_{t}, y\right)+(1-t) f\left(y_{t}, p\right) \leq t f\left(y_{t}, y\right) \text {. }
$$

Thus $f\left(y_{t}, y\right) \geq 0$. From (A3), we have $f(p, y) \geq 0$ for all $y \in C$. Hence $p \in \operatorname{EP}(f)$.

Step 7. We show that $x_{n} \rightarrow p \in F(T) \cap F(S)$.

From definition of $C_{n}$, we have

$$
\alpha_{n} \phi\left(z, x_{n}\right)+\left(1-\alpha_{n}\right) \phi\left(z, z_{n}\right) \leq \phi\left(z, x_{n}\right) \Longleftrightarrow \phi\left(z, z_{n}\right) \leq \phi\left(z, x_{n}\right) .
$$

Since $x_{n+1}=\prod_{C_{n+1}} x_{0} \in C_{n+1}$, we have

$$
\phi\left(x_{n+1}, z_{n}\right) \leq \phi\left(x_{n+1}, x_{n}\right) .
$$

It follows from (3.16) that

$$
\lim _{n \rightarrow \infty} \phi\left(x_{n+1}, z_{n}\right)=0,
$$

again from Lemma 2.3, we get

$$
\lim _{n \rightarrow \infty}\left\|x_{n+1}-z_{n}\right\|=0 .
$$


By using the triangle inequality, we get

$$
\left\|z_{n}-x_{n}\right\| \leq\left\|z_{n}-x_{n+1}\right\|+\left\|x_{n+1}-x_{n}\right\| .
$$

Again by (3.17) and (3.33), we also have

$$
\lim _{n \rightarrow \infty}\left\|z_{n}-x_{n}\right\|=0
$$

Since $J$ is uniformly norm-to-norm continuous, we obtain

$$
\lim _{n \rightarrow \infty}\left\|J z_{n}-J x_{n}\right\|=0 .
$$

Since

$$
\left\|y_{n}-z_{n}\right\| \leq\left\|y_{n}-u_{n}\right\|+\left\|u_{n}-x_{n}\right\|+\left\|x_{n}-z_{n}\right\|,
$$

from (3.22), (3.25), and (3.35), we have

$$
\lim _{n \rightarrow \infty}\left\|y_{n}-z_{n}\right\|=0
$$

Since $J$ is uniformly norm-to-norm continuous, we also have

$$
\lim _{n \rightarrow \infty}\left\|J y_{n}-J z_{n}\right\|=0
$$

From (3.1), we get

$$
\begin{aligned}
\left\|J y_{n}-J z_{n}\right\| & =\left\|\alpha_{n}\left(J x_{n}-J z_{n}\right)+\left(1-\alpha_{n}\right)\left(J S z_{n}-J z_{n}\right)\right\| \\
& =\left\|\left(1-\alpha_{n}\right)\left(J S z_{n}-J z_{n}\right)-\alpha_{n}\left(J z_{n}-J x_{n}\right)\right\| \\
& \geq\left(1-\alpha_{n}\right)\left\|J S z_{n}-J z_{n}\right\|-\alpha_{n}\left\|J z_{n}-J x_{n}\right\|
\end{aligned}
$$

it follows that

$$
\left(1-\alpha_{n}\right)\left\|J S z_{n}-J z_{n}\right\| \leq\left\|J y_{n}-J z_{n}\right\|+\alpha_{n}\left\|J z_{n}-J x_{n}\right\|,
$$

and hence

$$
\left\|J S z_{n}-J z_{n}\right\| \leq \frac{1}{1-\alpha_{n}}\left(\left\|J y_{n}-J z_{n}\right\|+\alpha_{n}\left\|J z_{n}-J x_{n}\right\|\right)
$$


Since $\alpha_{n} \leq 1-\delta_{1}$ for some $\delta_{1} \in(0,1)$, (3.36), and (3.39), one has $\lim _{n \rightarrow \infty}\left\|J S z_{n}-J z_{n}\right\|=0$. Since $J^{-1}$ is uniformly norm-to-norm continuous, we get

$$
\lim _{n \rightarrow \infty}\left\|S z_{n}-z_{n}\right\|=0
$$

Since

$$
\begin{aligned}
\left\|S x_{n}-x_{n}\right\| & \leq\left\|S x_{n}-S z_{n}\right\|+\left\|S z_{n}-z_{n}\right\|+\left\|z_{n}-x_{n}\right\| \\
& \leq\left\|x_{n}-z_{n}\right\|+\left\|S z_{n}-z_{n}\right\|+\left\|z_{n}-x_{n}\right\|
\end{aligned}
$$

from (3.35) and (3.43), we obtain

$$
\lim _{n \rightarrow \infty}\left\|S x_{n}-x_{n}\right\|=0
$$

Since $S$ is closed and $x_{n} \rightarrow p$, we have $p \in F(S)$.

On the other hand, we note that

$$
\begin{aligned}
\phi\left(q, x_{n}\right)-\phi\left(q, u_{n}\right) & =\left\|x_{n}\right\|^{2}-\left\|u_{n}\right\|^{2}-2\left\langle q, J x_{n}-J u_{n}\right\rangle \\
& \leq\left\|x_{n}-u_{n}\right\|\left(\left\|x_{n}+u_{n}\right\|\right)+2\|q\|\left\|J x_{n}-J u_{n}\right\| .
\end{aligned}
$$

It follows from $\left\|x_{n}-u_{n}\right\| \rightarrow 0$ and $\left\|J x_{n}-J u_{n}\right\| \rightarrow 0$, that

$$
\phi\left(q, x_{n}\right)-\phi\left(q, u_{n}\right) \longrightarrow 0
$$

Furthermore, from (3.4) and (3.5),

$$
\begin{aligned}
\phi\left(q, u_{n}\right) \leq & \phi\left(q, y_{n}\right) \\
\leq & \alpha_{n} \phi\left(q, x_{n}\right)+\left(1-\alpha_{n}\right) \phi\left(q, z_{n}\right) \\
\leq & \alpha_{n} \phi\left(q, x_{n}\right)+\left(1-\alpha_{n}\right)\left[\beta_{n} \phi\left(q, x_{n}\right)+\left(1-\beta_{n}\right) \phi\left(q, w_{n}\right)\right] \\
= & \alpha_{n} \phi\left(q, x_{n}\right)+\left(1-\alpha_{n}\right) \beta_{n} \phi\left(q, x_{n}\right)+\left(1-\alpha_{n}\right)\left(1-\beta_{n}\right) \phi\left(q, w_{n}\right) \\
\leq & \alpha_{n} \phi\left(q, x_{n}\right)+\left(1-\alpha_{n}\right) \beta_{n} \phi\left(q, x_{n}\right)+\left(1-\alpha_{n}\right)\left(1-\beta_{n}\right) \\
& \times\left[\phi\left(q, x_{n}\right)-2 \lambda_{n}\left(\alpha-\frac{2}{c^{2}} \lambda_{n}\right)\left\|A x_{n}-A q\right\|^{2}\right] \\
= & \alpha_{n} \phi\left(q, x_{n}\right)+\left(1-\alpha_{n}\right) \beta_{n} \phi\left(q, x_{n}\right)+\left(1-\alpha_{n}\right)\left(1-\beta_{n}\right) \phi\left(q, x_{n}\right) \\
& -\left(1-\alpha_{n}\right)\left(1-\beta_{n}\right) 2 \lambda_{n}\left(\alpha-\frac{2}{c^{2}} \lambda_{n}\right)\left\|A x_{n}-A q\right\|^{2} \\
= & \phi\left(q, x_{n}\right)-\left(1-\alpha_{n}\right)\left(1-\beta_{n}\right) 2 \lambda_{n}\left(\alpha-\frac{2}{c^{2}} \lambda_{n}\right)\left\|A x_{n}-A q\right\|^{2},
\end{aligned}
$$


and hence

$$
\begin{aligned}
\delta_{1} \delta_{2} 2 a\left(\alpha-\frac{2 a}{c^{2}}\right)\left\|A x_{n}-A q\right\|^{2} & \leq\left(1-\alpha_{n}\right)\left(1-\beta_{n}\right) 2 \lambda_{n}\left(\alpha-\frac{2}{c^{2}} \lambda_{n}\right)\left\|A x_{n}-A q\right\|^{2} \\
& \leq \phi\left(q, x_{n}\right)-\phi\left(q, u_{n}\right) .
\end{aligned}
$$

From (3.47) and (3.49), we have

$$
\left\|A x_{n}-A q\right\| \longrightarrow 0
$$

From Lemma 2.5, Lemma 2.10, and (3.8), we compute

$$
\begin{aligned}
\phi\left(x_{n}, w_{n}\right) & =\phi\left(x_{n}, \Pi_{C} J^{-1}\left(J x_{n}-\lambda_{n} A x_{n}\right)\right) \\
& \leq \phi\left(x_{n}, J^{-1}\left(J x_{n}-\lambda_{n} A x_{n}\right)\right) \\
& =V\left(x_{n}, J x_{n}-\lambda_{n} A x_{n}\right) \\
& \leq V\left(x_{n},\left(J x_{n}-\lambda_{n} A x_{n}\right)+\lambda_{n} A x_{n}\right)-2\left\langle J^{-1}\left(J x_{n}-\lambda_{n} A x_{n}\right)-x_{n}, \lambda_{n} A x_{n}\right\rangle \\
& =\phi\left(x_{n}, x_{n}\right)+2\left\langle J^{-1}\left(J x_{n}-\lambda_{n} A x_{n}\right)-x_{n},-\lambda_{n} A x_{n}\right\rangle \\
& =2\left\langle J^{-1}\left(J x_{n}-\lambda_{n} A x_{n}\right)-x_{n},-\lambda_{n} A x_{n}\right\rangle \\
& \leq \frac{4 \lambda_{n}^{2}}{c^{2}}\left\|A x_{n}-A q\right\|^{2} \\
& \leq \frac{4 b^{2}}{c^{2}}\left\|A x_{n}-A q\right\|^{2} .
\end{aligned}
$$

Applying Lemmas 2.3 and (3.50), we obtain that

$$
\left\|x_{n}-w_{n}\right\| \longrightarrow 0
$$

Again since $J$ is uniformly norm-to-norm continuous on bounded set, we have

$$
\left\|J x_{n}-J w_{n}\right\| \longrightarrow 0
$$

Since

$$
\left\|z_{n}-w_{n}\right\| \leq\left\|z_{n}-x_{n}\right\|+\left\|x_{n}-w_{n}\right\|
$$

by (3.35) and (3.52), we have

$$
\lim _{n \rightarrow \infty}\left\|z_{n}-w_{n}\right\|=0,
$$


and hence

$$
\lim _{n \rightarrow \infty}\left\|J z_{n}-J w_{n}\right\|=0
$$

From (3.1) we obtain that

$$
\begin{aligned}
\left\|J z_{n}-J w_{n}\right\| & =\left\|\beta_{n} J x_{n}+\left(1-\beta_{n}\right) J T w_{n}-J w_{n}\right\| \\
& \geq\left(1-\beta_{n}\right)\left\|J T w_{n}-J w_{n}\right\|-\beta_{n}\left\|J w_{n}-J x_{n}\right\|,
\end{aligned}
$$

and hence

$$
\left(1-\beta_{n}\right)\left\|J T w_{n}-J w_{n}\right\| \leq\left\|J z_{n}-J w_{n}\right\|+\beta_{n}\left\|J w_{n}-J x_{n}\right\|,
$$

so

$$
\left\|J T w_{n}-J w_{n}\right\| \leq \frac{1}{1-\beta_{n}}\left\|J z_{n}-J w_{n}\right\|+\beta_{n}\left\|J w_{n}-J x_{n}\right\|
$$

By (3.53), (3.56) and condition $\beta_{n} \leq 1-\delta_{2}$ for some $\delta_{2} \in(0,1)$, we obtain

$$
\left\|J T w_{n}-J w_{n}\right\| \longrightarrow 0
$$

Since $J^{-1}$ is uniformly norm-to-norm continuous on bounded set, we obtain

$$
\left\|T w_{n}-w_{n}\right\| \longrightarrow 0
$$

Since $x_{n} \rightarrow w_{n}$, then $\left\|T x_{n}-x_{n}\right\| \rightarrow 0$. Thus by the closedness of $T$ and $x_{n} \rightarrow p$, we get $p \in F(T)$. Hence $p \in F(T) \cap F(S)$.

Step 8. We show that $x_{n} \rightarrow p \in \operatorname{VI}(A, C)$.

Define $T \subset E \times E^{*}$ by Theorem 2.11; $T$ is maximal monotone and $T^{-1} 0=\operatorname{VI}(A, C)$. Let $(v, w) \in G(T)$. Since $w \in T v=A v+N_{C}(v)$, we get $w-A v \in N_{C}(v)$.

From $w_{n} \in C$, we have

$$
\left\langle v-w_{n}, w-A v\right\rangle \geq 0
$$

On the other hand, since $w_{n}=\Pi_{C} J^{-1}\left(J x_{n}-\lambda_{n} A x_{n}\right)$, then by Lemma 2.4, we have

$$
\left\langle v-w_{n}, J w_{n}-\left(J x_{n}-\lambda_{n} A x_{n}\right)\right\rangle \geq 0,
$$

and hence

$$
\left\langle v-w_{n}, \frac{J x_{n}-J w_{n}}{\lambda_{n}}-A x_{n}\right\rangle \leq 0 .
$$


It follows from (3.62) and (3.64), that

$$
\begin{aligned}
\left\langle v-w_{n}, w\right\rangle & \geq\left\langle v-w_{n}, A v\right\rangle \\
& \geq\left\langle v-w_{n}, A v\right\rangle+\left\langle v-w_{n}, \frac{J x_{n}-J w_{n}}{\lambda_{n}}-A x_{n}\right\rangle \\
& =\left\langle v-w_{n}, A v-A x_{n}\right\rangle+\left\langle v-w_{n}, \frac{J x_{n}-J w_{n}}{\lambda_{n}}\right\rangle \\
& =\left\langle v-w_{n}, A v-A w_{n}\right\rangle+\left\langle v-w_{n}, A w_{n}-A x_{n}\right\rangle+\left\langle v-w_{n}, \frac{J x_{n}-J w_{n}}{\lambda_{n}}\right\rangle \\
& \geq-\left\|v-w_{n}\right\| \frac{\left\|w_{n}-x_{n}\right\|}{\alpha}-\left\|v-w_{n}\right\| \frac{\left\|J x_{n}-J w_{n}\right\|}{a} \\
& \geq-M\left(\frac{\left\|w_{n}-x_{n}\right\|}{\alpha}+\frac{\left\|J x_{n}-J w_{n}\right\|}{a}\right) .
\end{aligned}
$$

Where $M=\sup _{n \geq 1}\left\|v-w_{n}\right\|$. Taking the limit as $n \rightarrow \infty$ and (3.53), we obtain $\langle v-p, w\rangle \geq 0$. By the maximality of $T$, we have $p \in T^{-1} 0$; that is, $p \in \operatorname{VI}(A, C)$.

Step 9. We show that $p=\Pi_{\Omega} x_{0}$.

From $x_{n}=\Pi_{C_{n}} x_{0}$, we have $\left\langle J x_{0}-J x_{n}, x_{n}-z\right\rangle \geq 0, \forall z \in C_{n}$. Since $\Omega \subset C_{n}$, we also have

$$
\left\langle J x_{0}-J x_{n}, x_{n}-y\right\rangle \geq 0, \quad \forall y \in \Omega
$$

By taking limit $n \rightarrow \infty$, we obtain that

$$
\left\langle J x_{0}-J p, p-y\right\rangle \geq 0, \quad \forall y \in \Omega
$$

By Lemma 2.4, we can conclude that $p=\Pi_{\Omega} x_{0}$ and $x_{n} \rightarrow p$ as $n \rightarrow \infty$. This completes the proof.

Setting $S \equiv T$ in Theorem 3.1., so, we obtain the following corollary.

Corollary 3.2. Let $C$ be a nonempty closed and convex subset of a 2-uniformly convex and uniformly smooth Banach space $E$. Let $f$ be a bifunction from $C \times C$ to $\mathbb{R}$ satisfying (A1)-(A4) and let $A$ be an $\alpha$-inverse-strongly monotone mapping of $C$ into $E^{*}$ satisfying $\|A y\| \leq\|A y-A u\|$, for all $y \in C$ and $u \in \operatorname{VI}(A, C) \neq \emptyset$. Let $T: C \rightarrow C$ be closed relatively quasi-nonexpansive mappings such that 
$\Omega:=F(T) \cap \operatorname{EP}(f) \cap \operatorname{VI}(A, C) \neq \emptyset$. For an initial point $x_{0} \in E$ with $x_{1}=\Pi_{C_{1}} x_{0}$ and $C_{1}=C$, define a sequence $\left\{x_{n}\right\}$ as follows:

$$
\begin{gathered}
w_{n}=\Pi_{C} J^{-1}\left(J x_{n}-\lambda_{n} A x_{n}\right), \\
z_{n}=J^{-1}\left(\beta_{n} J x_{n}+\left(1-\beta_{n}\right) J T w_{n}\right), \\
y_{n}=J^{-1}\left(\alpha_{n} J x_{n}+\left(1-\alpha_{n}\right) J T z_{n}\right), \\
u_{n} \in C \quad \text { such that } f\left(u_{n}, y\right)+\frac{1}{r_{n}}\left\langle y-u_{n}, J u_{n}-J y_{n}\right\rangle \geq 0, \quad \forall y \in C, \\
C_{n+1}=\left\{z \in C_{n}: \phi\left(z, u_{n}\right) \leq \alpha_{n} \phi\left(z, x_{n}\right)+\left(1-\alpha_{n}\right) \phi\left(z, z_{n}\right) \leq \phi\left(z, x_{n}\right)\right\}, \\
x_{n+1}=\prod_{C_{n+1}} x_{0}, \quad \forall n \geq 1,
\end{gathered}
$$

where $J$ is the duality mapping on E. Assume that $\left\{\alpha_{n}\right\}$ and $\left\{\beta_{n}\right\}$ are sequences in $[0,1]$ such that $\alpha_{n} \leq 1-\delta_{1}$ and $\beta_{n} \leq 1-\delta_{2}$, for some $\delta_{1}, \delta_{2} \in(0,1),\left\{r_{n}\right\} \subseteq(0,2 \alpha)$, and $\left\{\lambda_{n}\right\} \subset[a, b]$ for some $a, b$ with $0<a<b<c^{2} \alpha / 2$, where $1 / c$ is the 2-uniformly convexity constant of $E$. Then $\left\{x_{n}\right\}$ converges strongly to $p \in \Omega$, where $p=\Pi_{\Omega} x_{0}$.

If $A \equiv 0$ in Theorem 3.1, then we obtain the following corollary.

Corollary 3.3. Let $C$ be a nonempty closed and convex subset of a 2-uniformly convex and uniformly smooth Banach space $E$. Let $f$ be a bifunction from $C \times C$ to $\mathbb{R}$ satisfying (A1)-(A4). Let $T, S: C \rightarrow C$ is closed relatively quasi-nonexpansive mappings such that $\Omega:=F(T) \cap F(S) \cap \operatorname{EP}(f) \neq \emptyset$. For an initial point $x_{0} \in E$ with $x_{1}=\Pi_{C_{1}} x_{0}$ and $C_{1}=C$, define a sequence $\left\{x_{n}\right\}$ as follows:

$$
\begin{gathered}
z_{n}=J^{-1}\left(\beta_{n} J x_{n}+\left(1-\beta_{n}\right) J T w_{n}\right), \\
y_{n}=J^{-1}\left(\alpha_{n} J x_{n}+\left(1-\alpha_{n}\right) J S z_{n}\right), \\
u_{n} \in C \quad \text { such that } f\left(u_{n}, y\right)+\frac{1}{r_{n}}\left\langle y-u_{n}, J u_{n}-J y_{n}\right\rangle \geq 0, \quad \forall y \in C, \\
C_{n+1}=\left\{z \in C_{n}: \phi\left(z, u_{n}\right) \leq \alpha_{n} \phi\left(z, x_{n}\right)+\left(1-\alpha_{n}\right) \phi\left(z, z_{n}\right) \leq \phi\left(z, x_{n}\right)\right\}, \\
x_{n+1}=\prod_{C_{n+1}} x_{0}, \quad \forall n \geq 1,
\end{gathered}
$$

where $J$ is the duality mapping on E. Assume that $\left\{\alpha_{n}\right\}$ and $\left\{\beta_{n}\right\}$ are sequences in $[0,1]$ such that $\alpha_{n} \leq 1-\delta_{1}$ and $\beta_{n} \leq 1-\delta_{2}$, for some $\delta_{1}, \delta_{2} \in(0,1)$ and $\left\{r_{n}\right\} \subseteq(0,2 \alpha)$. Then $\left\{x_{n}\right\}$ converges strongly to $p \in \Omega$, where $p=\Pi_{\Omega} x_{0}$. 


\section{Application}

\subsection{Complementarity Problem}

Let $K$ be a nonempty, closed and convex cone $E$, A a mapping of $K$ into $E^{*}$. We define its polar in $E^{*}$ to be the set

$$
K^{*}=\left\{y^{*} \in E^{*}:\left\langle x, y^{*}\right\rangle \geq 0, \forall x \in K\right\}
$$

Then the element $u \in K$ is called a solution of the complementarity problem if

$$
A u \in K^{*},\langle u, A u\rangle=0 .
$$

The set of solutions of the complementarity problem is denoted by $C(K, A)$.

Theorem 4.1. Let $K$ be a nonempty and closed convex subset of a 2-uniformly convex and uniformly smooth Banach space E. Let $f$ be a bifunction from $K \times K$ to $\mathbb{R}$ satisfying (A1)-(A4) and let $A$ be an $\alpha$-inverse-strongly monotone of $E$ into $E^{*}$ satisfying $\|A y\| \leq\|A y-A u\|$, for all $y \in K$ and $u \in C(K, A) \neq \emptyset$. Let $T, S: K \rightarrow K$ be closed relatively quasi-nonexpansive mappings and $\Omega:=$ $F(T) \cap F(S) \cap \operatorname{EP}(f) \cap C(K, A) \neq \emptyset$. For an initial point $x_{0} \in E$ with $x_{1}=\Pi_{K_{1}}$ and $K_{1}=K$, we define the sequence $\left\{x_{n}\right\}$ as follows:

$$
\begin{gathered}
w_{n}=\Pi_{K} J^{-1}\left(J x_{n}-\lambda_{n} A x_{n}\right), \\
z_{n}=J^{-1}\left(\beta_{n} J x_{n}+\left(1-\beta_{n}\right) J T w_{n}\right), \\
y_{n}=J^{-1}\left(\alpha_{n} J x_{n}+\left(1-\alpha_{n}\right) J S z_{n}\right), \\
u_{n} \in C \quad \text { such that } f\left(u_{n}, y\right)+\frac{1}{r_{n}}\left\langle y-u_{n}, J u_{n}-J y_{n}\right\rangle \geq 0, \quad \forall y \in K, \\
C_{n+1}=\left\{z \in C_{n}: \phi\left(z, u_{n}\right) \leq \alpha_{n} \phi\left(z, x_{n}\right)+\left(1-\alpha_{n}\right) \phi\left(z, z_{n}\right) \leq \phi\left(z, x_{n}\right)\right\}, \\
x_{n+1}=\prod_{C_{n+1}} x_{0}, \quad \forall n \geq 1,
\end{gathered}
$$

where $J$ is the duality mapping on $E,\left\{\alpha_{n}\right\}$ and $\left\{\beta_{n}\right\}$ are sequences in $[0,1]$ such that $\alpha_{n} \leq 1-\delta_{1}$ and $\beta_{n} \leq 1-\delta_{2}$, for some $\delta_{1}, \delta_{2} \in(0,1),\left\{r_{n}\right\} \subseteq(0,2 \alpha)$, and $\left\{\lambda_{n}\right\} \subset[a, b]$ for some $a, b$ with $0<a<b<c^{2} \alpha / 2$, where $1 / c$ is the 2-uniformly convexity constant of $E$. Then $\left\{x_{n}\right\}$ converges strongly to $p \in \Omega$, where $p=\Pi_{\Omega} x_{0}$.

Proof. As in the proof of Takahashi in [7, Lemma 7.11], we get that $\operatorname{VI}(K, A)=C(K, A)$. So, we obtain the result.

\subsection{Approximation of a Zero of a Maximal Monotone Operator}

Let $B$ be a multivalued mapping from $E$ to $E^{*}$ with domain $D(B)=\{z \in E: A z \neq \emptyset\}$ and range $R(B)=\cup\{B z: z \in D(B)\}$. A mapping $B$ is said to be a monotone operator if $\left\langle x_{1}-x_{2}, y_{1}-y_{2}\right\rangle \geq 0$ for each $x_{i} \in D(B)$ and $y_{i} \in A x_{i}, i=1,2$. A monotone operator $B$ is said to be maximal if 
its graph $G(B)=\{(x, y): y \in A x\}$ is not property contained in the graph of any other monotone operator. We know that if $B$ is a maximal monotone operator, then $B^{-1}(0)$ is closed and convex. Let $E$ be a reflexive, strictly convex, and smooth Banach space, and let $B$ be a monotone operator from $E$ to $E^{*}$, we know that $B$ is maximal if and only if $R(J+r B)=E^{*}$ for all $r>0$. Let $J_{r}: E \rightarrow D(B)$ be defined by $J_{r}=(J+r B)^{-1}$ Jand such a $J_{r}$ is called the resolvent of $B$. We know that $J_{r}$ is a relatively nonexpansive (closed relatively quasi-nonexpansive for example; see [8]), and $B^{-1}(0)=F\left(J_{r}\right)$ for all $r>0$ (see [7, 33-35] for more details).

Theorem 4.2. Let $C$ be a nonempty and closed convex subset of a 2-uniformly convex and uniformly smooth Banach space $E$. Let $f$ be a bifunction from $C \times C$ to $\mathbb{R}$ satisfying (A1)-(A4) and let $A$ be $\alpha$-inverse-strongly monotone of $E$ into $E^{*}$ satisfying $\|A y\| \leq\|A y-A u\|$, for all $y \in C$ and $u \in \operatorname{VI}(A, C) \neq \emptyset$. Let $B$ be a maximal monotone operator of $E$ into $E^{*}$ and let $J_{r}$ be a resolvent of $B$ and a closed mapping such that $\Omega:=B^{-1}(0) \cap F(S) \cap \operatorname{EP}(f) \cap \operatorname{VI}(A, C) \neq \emptyset$. For an initial point $x_{0} \in E$ with $x_{1}=\Pi_{C_{1}}$ and $C_{1}=C$, we define the sequence $\left\{x_{n}\right\}$ as follows:

$$
\begin{gathered}
w_{n}=\prod_{C} J^{-1}\left(J x_{n}-\lambda_{n} A x_{n}\right), \\
z_{n}=J^{-1}\left(\beta_{n} J x_{n}+\left(1-\beta_{n}\right) J J_{r} w_{n}\right), \\
y_{n}=J^{-1}\left(\alpha_{n} J x_{n}+\left(1-\alpha_{n}\right) J S z_{n}\right), \\
u_{n} \in C \quad \text { such that } f\left(u_{n}, y\right)+\frac{1}{r_{n}}\left\langle y-u_{n}, J u_{n}-J y_{n}\right\rangle \geq 0, \quad \forall y \in C, \\
C_{n+1}=\left\{z \in C_{n}: \phi\left(z, u_{n}\right) \leq \alpha_{n} \phi\left(z, x_{n}\right)+\left(1-\alpha_{n}\right) \phi\left(z, z_{n}\right) \leq \phi\left(z, x_{n}\right)\right\}, \\
x_{n+1}=\prod_{C_{n+1}} x_{0}, \quad \forall n \geq 1,
\end{gathered}
$$

where $J$ is the duality mapping on $E,\left\{\alpha_{n}\right\}$ and $\left\{\beta_{n}\right\}$ are sequences in $[0,1]$ such that $\alpha_{n} \leq 1-\delta_{1}$ and $\beta_{n} \leq 1-\delta_{2}$, for some $\delta_{1}, \delta_{2} \in(0,1),\left\{r_{n}\right\} \subseteq(0,2 \alpha)$ and $\left\{\lambda_{n}\right\} \subset[a, b]$ for some $a, b$ with $0<a<b<c^{2} \alpha / 2$, where $1 / c$ is the 2-uniformly convexity constant of $E$. Then $\left\{x_{n}\right\}$ converges strongly to $p \in \Omega$, where $p=\Pi_{\Omega} x_{0}$.

Proof. Since $J_{r}$ is a closed relatively nonexpansive mapping and $B^{-1} 0=F\left(J_{r}\right)$. So, we obtain the result.

Corollary 4.3. Let $C$ be a nonempty and closed convex subset of a 2-uniformly convex and uniformly smooth Banach space $E$. Let $f$ be a bifunction from $C \times C$ to $\mathbb{R}$ satisfying (A1)-(A4) and let $A$ be $\alpha$-inverse-strongly monotone of $E$ into $E^{*}$ satisfying $\|A y\| \leq\|A y-A u\|$, for all $y \in C$ and $u \in \operatorname{VI}(A, C) \neq \emptyset$. Let $B$ be a maximal monotone operator of $E$ into $E^{*}$ and let $J_{r}$ be a resolvent of $B$ and closed such that $\Omega:=B^{-1}(0) \cap \operatorname{EP}(f) \cap \operatorname{VI}(A, C) \neq \emptyset$. For an initial point $x_{0} \in E$ with $x_{1}=\Pi_{C_{1}}$ and $C_{1}=C$, we define the sequence $\left\{x_{n}\right\}$ as follows:

$$
\begin{gathered}
w_{n}=\prod_{C} J^{-1}\left(J x_{n}-\lambda_{n} A x_{n}\right), \\
z_{n}=J^{-1}\left(\beta_{n} J x_{n}+\left(1-\beta_{n}\right) J J_{r} w_{n}\right), \\
y_{n}=J^{-1}\left(\alpha_{n} J x_{n}+\left(1-\alpha_{n}\right) J J_{r} z_{n}\right), \\
u_{n} \in C \quad \text { such that } f\left(u_{n}, y\right)+\frac{1}{r_{n}}\left\langle y-u_{n}, J u_{n}-J y_{n}\right\rangle \geq 0, \quad \forall y \in C, \\
C_{n+1}=\left\{z \in C_{n}: \phi\left(z, u_{n}\right) \leq \alpha_{n} \phi\left(z, x_{n}\right)+\left(1-\alpha_{n}\right) \phi\left(z, z_{n}\right) \leq \phi\left(z, x_{n}\right)\right\}, \\
x_{n+1}=\prod_{C_{n+1}} x_{0}, \quad \forall n \geq 1,
\end{gathered}
$$


where $J$ is the duality mapping on $E,\left\{\alpha_{n}\right\}$ and $\left\{\beta_{n}\right\}$ are sequences in $[0,1]$ such that $\alpha_{n} \leq 1-\delta_{1}$ and $\beta_{n} \leq 1-\delta_{2}$, for some $\delta_{1}, \delta_{2} \in(0,1),\left\{r_{n}\right\} \subseteq(0,2 \alpha)$ and $\left\{\lambda_{n}\right\} \subset[a, b]$ for some $a, b$ with $0<a<b<c^{2} \alpha / 2$, where $1 / c$ is the 2-uniformly convexity constant of $E$. Then $\left\{x_{n}\right\}$ converges strongly to $p \in \Omega$, where $p=\Pi_{\Omega} x_{0}$.

\section{Acknowledgments}

The authors would like to thank the referee for the valuable suggestions on the manuscript. Siwaporn Saewan would like to thank the Office of the Higher Education Commission, Thailand for supporting by grant fund under the program Strategic Scholarships for Frontier Research Network for the Join Ph.D. Program Thai Doctoral degree for this research. Moreover, Poom Kumam was supported by the Thailand Research Fund and the Commission on Higher Education (MRG5180034).

\section{References}

[1] K. Ball, E. A. Carlen, and E. H. Lieb, "Sharp uniform convexity and smoothness inequalities for trace norms," Inventiones Mathematicae, vol. 115, no. 3, pp. 463-482, 1994.

[2] Y. Takahashi, K. Hashimoto, and M. Kato, "On sharp uniform convexity, smoothness, and strong type, cotype inequalities," Journal of Nonlinear and Convex Analysis, vol. 3, no. 2, pp. 267-281, 2002.

[3] Y. I. Alber and S. Reich, "An iterative method for solving a class of nonlinear operator equations in Banach spaces," Panamerican Mathematical Journal, vol. 4, no. 2, pp. 39-54, 1994.

[4] Y. I. Alber, "Metric and generalized projection operators in Banach spaces: properties and applications," in Theory and Applications of Nonlinear Operators of Accretive and Monotone Type, vol. 178 of Lecture Notes in Pure and Applied Mathematics, pp. 15-50, Marcel Dekker, New York, NY, USA, 1996.

[5] I. Cioranescu, Geometry of Banach Spaces, Duality Mappings and Nonlinear Problems, vol. 62 of Mathematics and Its Applications, Kluwer Academic Publishers, Dordrecht, The Netherlands, 1990.

[6] S. Kamimura and W. Takahashi, "Strong convergence of a proximal-type algorithm in a Banach space," SIAM Journal on Optimization, vol. 13, no. 3, pp. 938-945, 2002.

[7] W. Takahashi, Nonlinear Functional Analysis, Yokohama Publishers, Yokohama, Japan, 2000, Fixed Point Theory and Its Application.

[8] X. Qin, Y. J. Cho, and S. M. Kang, "Convergence theorems of common elements for equilibrium problems and fixed point problems in Banach spaces," Journal of Computational and Applied Mathematics, vol. 225, no. 1, pp. 20-30, 2009.

[9] E. Blum and W. Oettli, "From optimization and variational inequalities to equilibrium problems," The Mathematics Student, vol. 63, no. 1-4, pp. 123-145, 1994.

[10] P. L. Combettes and S. A. Hirstoaga, "Equilibrium programming in Hilbert spaces," Journal of Nonlinear and Convex Analysis, vol. 6, no. 1, pp. 117-136, 2005.

[11] A. Moudafi, "Second-order differential proximal methods for equilibrium problems," Journal of Inequalities in Pure and Applied Mathematics, vol. 4, no. 1, article 18, 7 pages, 2003.

[12] S. Reich, "A weak convergence theorem for the alternating method with Bregman distances," in Theory and Applications of Nonlinear Operators of Accretive and Monotone Type, vol. 178 of Lecture Notes in Pure and Applied Mathematics, pp. 313-318, Marcel Dekker, New York, NY, USA, 1996.

[13] W. Nilsrakoo and S. Saejung, "Strong convergence to common fixed points of countable relatively quasi-nonexpansive mappings," Fixed Point Theory and Applications, vol. 2008, Article ID 312454, 19 pages, 2008.

[14] Y. Su, D. Wang, and M. Shang, "Strong convergence of monotone hybrid algorithm for hemi-relatively nonexpansive mappings," Fixed Point Theory and Applications, vol. 2008, Article ID 284613, 8 pages, 2008.

[15] H. Zegeye and N. Shahzad, "Strong convergence theorems for monotone mappings and relatively weak nonexpansive mappings," Nonlinear Analysis: Theory, Methods E Applications, vol. 70, no. 7, pp. 2707-2716, 2009. 
[16] D. Butnariu, S. Reich, and A. J. Zaslavski, "Asymptotic behavior of relatively nonexpansive operators in Banach spaces," Journal of Applied Analysis, vol. 7, no. 2, pp. 151-174, 2001.

[17] D. Butnariu, S. Reich, and A. J. Zaslavski, "Weak convergence of orbits of nonlinear operators in reflexive Banach spaces," Numerical Functional Analysis and Optimization, vol. 24, no. 5-6, pp. 489-508, 2003.

[18] Y. Censor and S. Reich, "Iterations of paracontractions and firmly nonexpansive operators with applications to feasibility and optimization," Optimization, vol. 37, no. 4, pp. 323-339, 1996.

[19] S. Matsushita and W. Takahashi, "A strong convergence theorem for relatively nonexpansive mappings in a Banach space," Journal of Approximation Theory, vol. 134, no. 2, pp. 257-266, 2005.

[20] H. Iiduka, W. Takahashi, and M. Toyoda, "Approximation of solutions of variational inequalities for monotone mappings," Panamerican Mathematical Journal, vol. 14, no. 2, pp. 49-61, 2004.

[21] H. Iiduka and W. Takahashi, "Weak convergence of a projection algorithm for variational inequalities in a Banach space," Journal of Mathematical Analysis and Applications, vol. 339, no. 1, pp. 668-679, 2008.

[22] S. Matsushita and W. Takahashi, "Weak and strong convergence theorems for relatively nonexpansive mappings in Banach spaces," Fixed Point Theory and Applications, vol. 2004, no. 1, pp. 37-47, 2004.

[23] W. Takahashi and K. Zembayashi, "Strong and weak convergence theorems for equilibrium problems and relatively nonexpansive mappings in Banach spaces," Nonlinear Analysis: Theory, Methods $\mathcal{E}$ Applications, vol. 70, no. 1, pp. 45-57, 2009.

[24] W. Takahashi and K. Zembayashi, "Strong convergence theorem by a new hybrid method for equilibrium problems and relatively nonexpansive mappings," Fixed Point Theory and Applications, vol. 2008, Article ID 528476, 11 pages, 2008.

[25] X. Qin and Y. Su, "Strong convergence theorems for relatively nonexpansive mappings in a Banach space," Nonlinear Analysis: Theory, Methods E Applications, vol. 67, no. 6, pp. 1958-1965, 2007.

[26] L. Wei, Y. J. Cho, and H. Zhou, "A strong convergence theorem for common fixed points of two relatively nonexpansive mappings and its applications," Journal of Applied Mathematics and Computing, vol. 29, no. 1-2, pp. 95-103, 2009.

[27] P. Cholamjiak, "A hybrid iterative scheme for equilibrium problems, variational inequality problems, and fixed point problems in Banach spaces," Fixed Point Theory and Applications, vol. 2009, Article ID 719360, 18 pages, 2009.

[28] P. Kumam and K. Wattanawitoon, "Convergence theorems of a hybrid algorithm for equilibrium problems," Nonlinear Analysis: Hybrid Systems, vol. 3, no. 4, pp. 386-394, 2009.

[29] B. Beauzamy, Introduction to Banach Spaces and Their Geometry, North-Holland, Amsterdam, The Netherlands, 2nd edition, 1995.

[30] H. K. Xu, "Inequalities in Banach spaces with applications," Nonlinear Analysis: Theory, Methods $\mathcal{E}$ Applications, vol. 16, no. 12, pp. 1127-1138, 1991.

[31] C. Zălinescu, "On uniformly convex functions," Journal of Mathematical Analysis and Applications, vol. 95, no. 2, pp. 344-374, 1983.

[32] R. T. Rockafellar, "On the maximality of sums of nonlinear monotone operators," Transactions of the American Mathematical Society, vol. 149, pp. 75-88, 1970.

[33] F. Kohsaka and W. Takahashi, "Strong convergence of an iterative sequence for maximal monotone operators in a Banach space," Abstract and Applied Analysis, no. 3, pp. 239-249, 2004.

[34] S. Plubtieng and W. Sriprad, "An extragradient method and proximal point algorithm for inverse strongly monotone operators and maximal monotone operators in Banach spaces," Fixed Point Theory and Applications, vol. 2009, Article ID 591874, 16 pages, 2009.

[35] S. Plubtieng and W. Sriprad, "Strong and weak convergence of modified Mann iteration for new resolvents of maximal monotone operators in Banach spaces," Abstract and Applied Analysis, vol. 2009, Article ID 795432, 20 pages, 2009. 


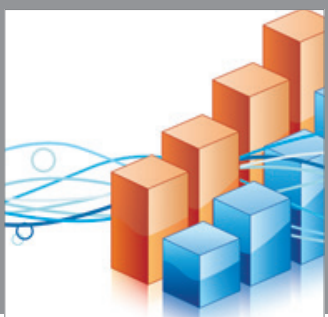

Advances in

Operations Research

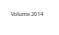

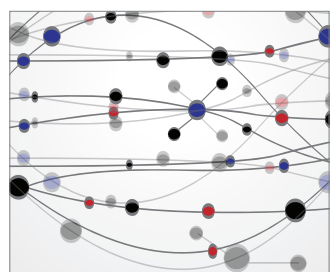

\section{The Scientific} World Journal
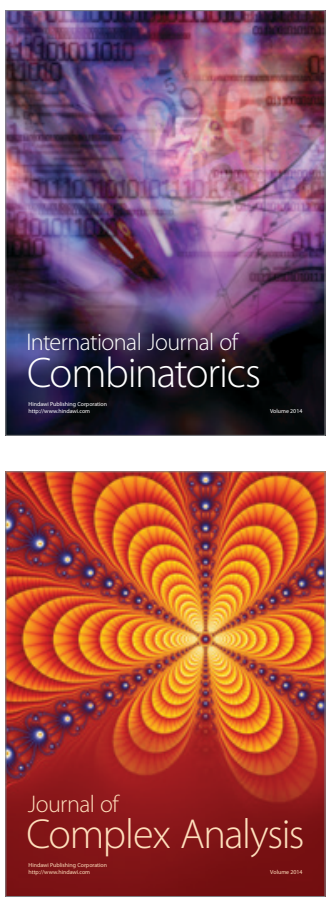

International Journal of

Mathematics and

Mathematical

Sciences
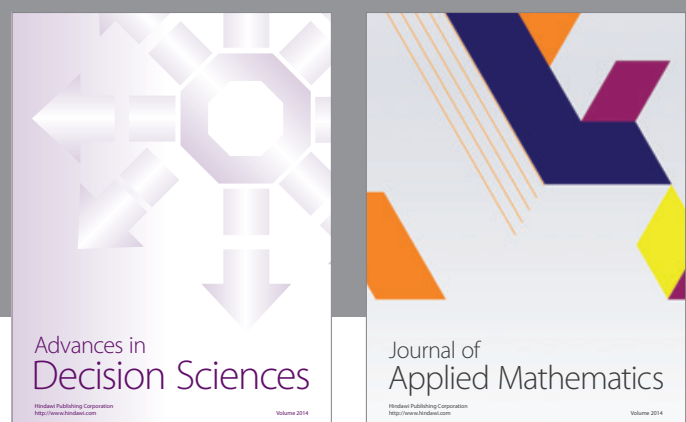

Journal of

Applied Mathematics
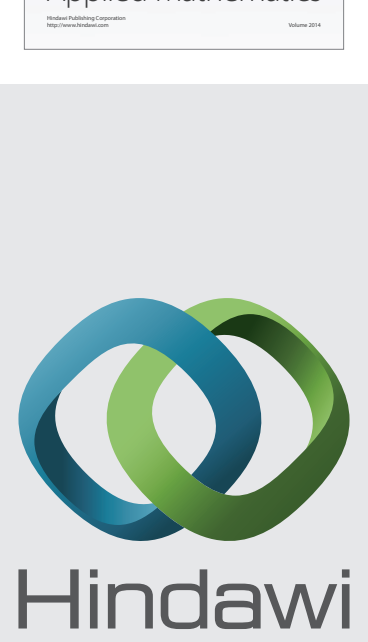

Submit your manuscripts at http://www.hindawi.com
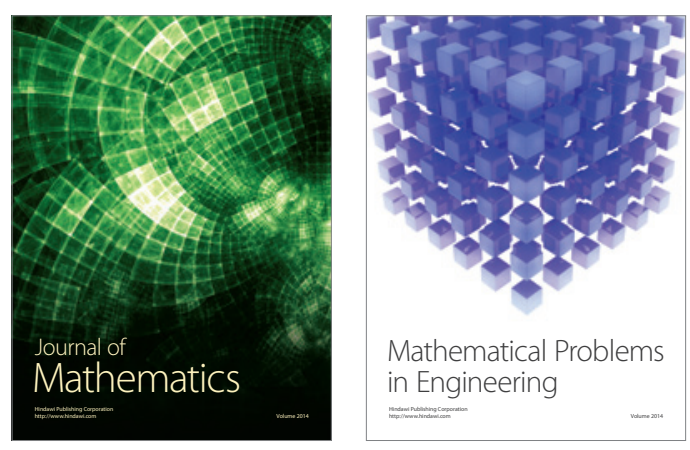

Mathematical Problems in Engineering
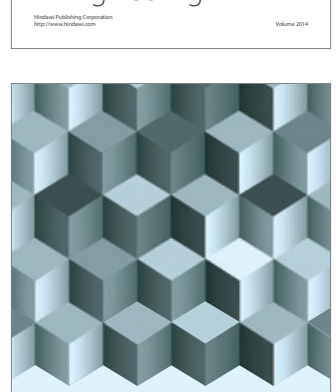

Journal of

Function Spaces
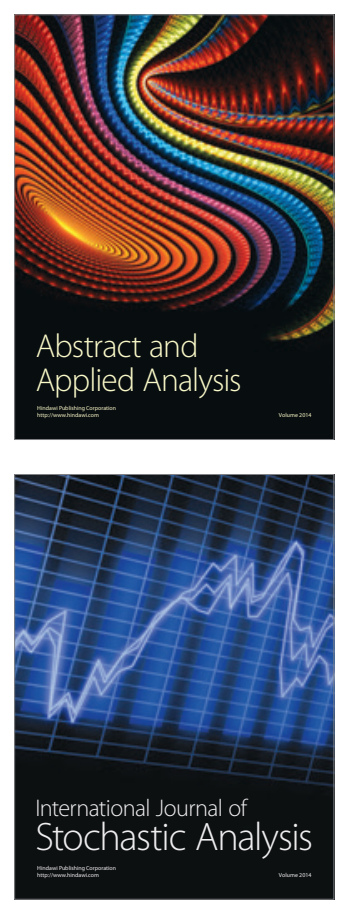

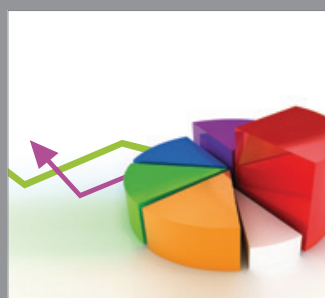

ournal of

Probability and Statistics

Promensencen
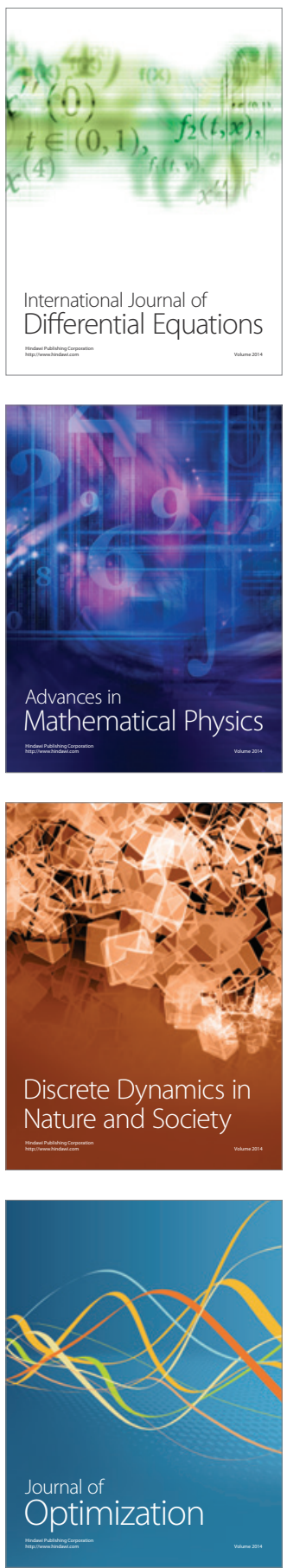